AperTO - Archivio Istituzionale Open Access dell'Università di Torino

\title{
Anticoagulation for central venous catheters in patients with cancer.
}

\section{This is the author's manuscript}

Original Citation:

\section{Availability:}

This version is available http://hdl.handle.net/2318/149219

since 2016-11-11T12:53:48Z

Published version:

DOI:10.1056/NEJMc1408861

Terms of use:

Open Access

Anyone can freely access the full text of works made available as "Open Access". Works made available under a Creative Commons license can be used according to the terms and conditions of said license. Use of all other works requires consent of the right holder (author or publisher) if not exempted from copyright protection by the applicable law. 


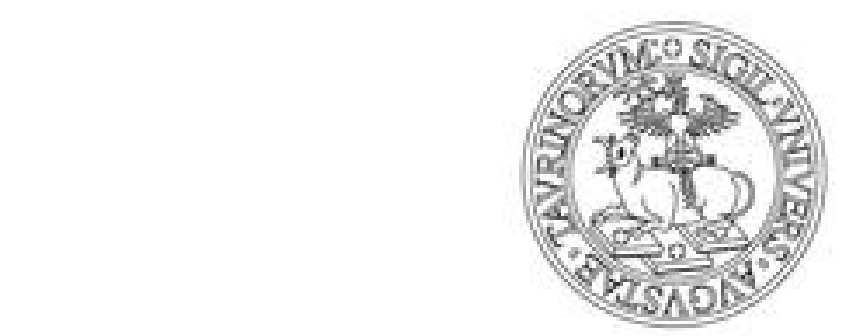

\section{UNIVERSITÀ DEGLI STUDI DI TORINO}

This is an author version of the contribution published on:

D'Ambrosio L,Aglietta M,Grignani G

Anticoagulation for central venous catheters in patients with cancer. NEW ENGLAND JOURNAL OF MEDICINE (2014) Oct 2;371

DOI: 10.1056/NEJMc1408861

The definitive version is available at:

http://www.nejm.org/doi/abs/10.1056/NEJMc1408861 


\section{Central venous catheter-associated venous thromboembolism in patients with cancer.}

Central venous catheters (CVC) are increasingly used in medical practice world-wide and, regardless the differences among the various $\mathrm{CVC},{ }^{1}$ these devices cause an increased risk of venous thromboembolism (VTE). ${ }^{2}$ The magnitude of the problem is highly dependent on whether we consider symptomatic (0.3$28.3 \%$ ) or asymptomatic VTE (27-66\%), ${ }^{2}$ and the diagnostic imaging technique used, being venography the most sensitive one. ${ }^{2}$ At any rate, CVC-associated VTE represents a major clinical problem in terms of venous access loss, pulmonary embolism and additional costs. ${ }^{3}$

This issue may be of even greater relevance in cancer patients who combine the need of CVC insertion with an intrinsic increased risk of VTE related to the tumor itself. Therefore, the question on how to reduce the risk of VTE in cancer patients harboring CVC is not trivial. Of course, the expected benefit of any prophylactic treatment is highly dependent on the absolute VTE risk that vary according to the different tumor histotypes and clinical presentations (e.g., pancreatic cancer or mediastinal syndrome). ${ }^{2}$ Several authors explored whether or not anticoagulant therapies (AT) (low-molecular weight heparin or vitamin K antagonists) can prevent CVC-associated VTE. ${ }^{1}$ In general, published data did not support systematic use of $\mathrm{AT},{ }^{1,3,4}$ but there are some conflicting data. ${ }^{5}$ This relative uncertainty prompted us to review the literature searching for randomized studies on the role of AT in the prevention of VTE in cancer patients harboring CVC.

On this specific issue we could identify 12 papers (most included in a recent Cochrane meta-analysis) suitable to evaluate the benefit of AT in cancer patients to prevent CVC-associated VTE. ${ }^{4,5}$ Our analysis was focused on symptomatic VTE only, because previous analyses did not demonstrate a statistically significant increase in bleeding risk,,$^{2,3,4}$ and we did not consider the prevention of asymptomatic VTE as a convincing endpoint.

In detail, data from 3018 patients enrolled in 12 randomized trials were included in this meta-analysis. Summary of Mantel-Haenszel risk ratios was calculated using a random-effects model. Our meta-analysis (Figure 1) suggests that AT compared to no active treatment significantly reduces the risk of symptomatic VTE (risk ratio $=0.61 ; 95 \%$ CI: $0.42-0.88$ ). The absolute incidence of VTE was reduced from $6.8 \%$ to $3.7 \%$ $(\mathrm{p}=0.0001)$ with 32 patients $(95 \% \mathrm{CI}: 21-65)$ needed to be treated to prevent one event. Although our findings argue in favor of AT for the prevention of CVC-associated VTE in cancer patients, only a large prospective randomized trial will definitely answer this question.

Lorenzo D'Ambrosio, M.D.

Massimo Aglietta, M.D.

Giovanni Grignani, M.D.

Istituto di Candiolo - Fondazione del Piemonte per l'Oncologia, IRCCS

Candiolo, Italy

giovanni.grignani@ircc.it 


\begin{tabular}{|c|c|c|c|c|c|}
\hline \multirow[b]{2}{*}{ Study or Subgroup } & \multicolumn{2}{|c|}{ Anticoagulation therapies } & \multicolumn{2}{|c|}{ Control } & \multirow[b]{2}{*}{ Weight } \\
\hline & Events & Total & Events & Total & \\
\hline Abdelkefi $2004^{4}$ & 1 & 38 & 5 & 36 & $3.0 \%$ \\
\hline Bern $1990^{4}$ & 4 & 54 & 13 & 54 & $11.1 \%$ \\
\hline Couban $2005^{4 *}$ & 6 & 130 & 5 & 125 & $9.3 \%$ \\
\hline De Cicco 20094 & 4 & 234 & 3 & 114 & $5.9 \%$ \\
\hline Heaton $2002^{4}$ & 2 & 45 & 1 & 43 & $2.4 \%$ \\
\hline Karthaus $2006^{4}$ & 10 & 294 & 5 & 145 & $11.1 \%$ \\
\hline Lavau-Denes $2013^{5}$ & 2 & 272 & 6 & 135 & $5.2 \%$ \\
\hline Monreal $1996^{4}$ & 1 & 16 & 5 & 13 & $3.3 \%$ \\
\hline Niers $2007^{4}$ & 0 & 41 & 1 & 46 & $1.4 \%$ \\
\hline Ruud 2006 & 1 & 29 & 1 & 33 & $1.8 \%$ \\
\hline Verso $2005^{4}$ & 2 & 155 & 6 & 155 & $5.2 \%$ \\
\hline Young 20094 & 30 & 408 & 38 & 403 & $40.3 \%$ \\
\hline Total $(95 \% \mathrm{Cl})$ & & 1716 & & 1302 & $100.0 \%$ \\
\hline Total events & 63 & & 89 & & \\
\hline
\end{tabular}

Risk Ratio

Risk Ratio

Random, 95\% Cl

M-H, Random, 95\% Cl

$0.31[0.11,0.88]$

$1.15[0.36,3.68]$

$0.65[0.15,2.85]$

$1.91[0.18,20.32]$

$0.99[0.34,2.83]$

$0.17[0.03,0.81]$

$0.16[0.02,1.22]$

$0.37[0.02,8.91]$

$1.14[0.07,17.39]$

$0.33[0.07,1.63]$

$0.78[0.49,1.23]$

$0.61[0.42,0.88]$

Test for overall effect: $Z=2.64$ ( $P=0.008$ )

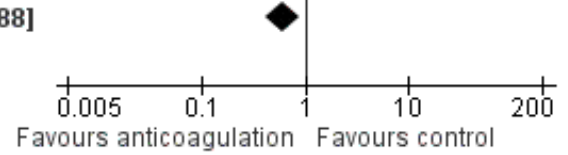

\section{Legend: Figure 1. Meta-analysis of randomized trials comparing anticoagulation therapies (either heparin or vitamin $\mathrm{K}$ antagonists) vs. untreated controls for symptomatic venous thromboembolism (VTE) in cancer patients harboring a central venous catheter.}

* The trial by Couban and Colleagues was excluded from previous Cochrane Review ${ }^{4}$ because of differential follow-up relative to randomization between the two arms (63 days for the warfarin group and 84 days for the placebo group).

** Regarding the trial of Ruud and Colleagues, we considered VTE as symptomatic in the presence of all the following three criteria: non compressibility of vein, absence of flow and presence of completely occluding thrombus.

1. Chopra V, Anand S, Hickner A, et al. Risk of venous thromboembolism associated with peripherally inserted central catheters: a systematic review and meta-analysis. Lancet 2013;382:311-25.

2. Verso M and Agnelli G. Venous thromboembolism associated with long-term use of central venous catheters in cancer patients. J Clin Oncol 2003;21:3665-75.

3. Debordeau P, Farge D, Beckers M et al. International clinical practice guidelines for the treatment and prophylaxis of thrombosis associated with central venous catheters in patients with cancer. J Thromb Haemost 2013;11:71-80.

4. Akl EA, Vasireddi SR, Gunukula S, et al. Anticoagulation for patients with cancer and central venous catheters. Cochrane Database Syst Rev 2011;2:CD006468.

5. Lavau-Denes S, Lacroix P, Maubon A, et al. Prophylaxis of catheter-related deep vein thrombosis in cancer patients with low-dose warfarin, low molecular weight heparin, or control: a randomized, controlled, phase III study. Cancer Chemother Pharmacol 2013;72:65-73. 